\title{
As barreiras à expressão da criatividade que podem influenciar na qualidade e inovação na TI
}

\author{
Angélica Toffano Seidel Calazans ${ }^{1}$ \\ Amélia Lima Guedes ${ }^{2}$
}

\section{Resumo}

A importância e necessidade da qualidade na TI já é consenso internacional. O impacto da inovação para o diferencial competitivo é também reconhecido por muitos autores e empresas. Considerada como componente conceitual da inovação, a criatividade tem sido incentivada por empresas que objetivam a melhoria contínua e a geração de produtos e serviços inovadores. Neste trabalho busca-se identificar a importância da criatividade para inovação e qualidade, mapeando as barreiras à sua expressão em uma área de TI de uma organização bancária governamental. Apresentam-se também algumas sugestões para o aprimoramento da criatividade organizacional.

Palavras-chave: Inovação. Criatividade. Qualidade. Barreiras de expressão à criatividade.

\section{Introdução}

Atualmente, desenvolver produtos de software com qualidade é essencial para se diferenciar no mercado. Além da qualidade, a inovação também representa um grande diferencial competitivo, pois o valor dos produtos e serviços depende cada vez mais dessa característica.

1 Doutora em Ciência da Informação, docente do Curso de Análise de Sistemas do Uniceub e Consultor TI da Caixa Econômica Federal.

2 Mestre em Gestão do Conhecimento e TI e Especialista da Caixa Econômica Federal. 
Considerada como um dos principais componentes da inovação, a criatividade tem sido estudada e estimulada nas organizações.

A criatividade é definida por Bruno-Faria e Alencar (1996) como um fenômeno multifacetado, envolvendo aspectos individuais (habilidades cognitivas, traços de personalidade) e do ambiente (aspectos facilitadores e inibidores). Assim, ser criativo é ver as coisas do mesmo modo que todo mundo vê, mas ser capaz de pensar de forma diferente sobre elas, e ainda ter a habilidade para produzir um ato que tanto é novo, original e inesperado, quanto útil, e adaptável às dificuldades das tarefas (STERNBERG; LUBART, 1999). E para Alencar (1997), a criatividade é um componente conceitual da inovação e é esta que permite a concretização e aplicação de novas ideias.

A criatividade no contexto organizacional permite às pessoas a geração de ideias inspiradoras que devem possuir um cunho prático. A inovação vem preencher essa necessidade, ou seja, a concretização ou implementação do pensamento criativo nas organizações. No contexto do segmento bancário, especificadamente na TI, existem áreas cuja missão envolve mais fortemente a melhoria contínua e a inovação. É o caso da área pesquisada em uma organização bancária federal, onde é a criatividade que possibilita a implementação de melhoria contínua dos processos e de ações inovadoras com relação a soluções negociais e tecnológicas.

No estudo da criatividade focado no ambiente organizacional, alguns autores como Alencar (1996) e Alencar e Fleith (2003) identificam e analisam possíveis barreiras e bloqueios à sua utilização.

O presente trabalho analisa as barreiras à expressão da criatividade e, por conseguinte, a qualidade e a inovação dos serviços e produtos gerados em uma área de TI de uma organização bancária. Inicialmente conceitua-se criatividade, sua importância para qualidade e inovação e as barreiras existentes para sua expressão. Logo a seguir, identifica-se sua importância no contexto bancário, foco da pesquisa, e apresentam-se os métodos utilizados e resultados obtidos pela pesquisa. Com base nesses resultados são propostas algumas alternativas para melhoria e conclui-se o trabalho identificando pesquisas futuras que poderiam ser realizadas no ambiente organizacional. 


\section{Criatividade}

Segundo Torrance (1962 apud NOVAES, 1980, p. 18),

A criatividade é o processo de tornar-se sensível a problemas, deficiências, lacunas no conhecimento, desarmonia; identificar a dificuldade, buscar soluções, formulando hipóteses a respeito das deficiências; testar e retestar essas hipóteses; e, finalmente, comunicar os resultados.

Essa definição pode ser complementada pela definição de Stein (apud ALENCAR, 1993), que afirma que "a criatividade é o processo que resulta em um produto novo, que é aceito como útil, e/ou satisfatório por um número significativo de pessoas em algum ponto no tempo", ou seja, com qualidade.

Alencar (1996) propõe um modelo para desenvolvimento da criatividade que abrange cinco componentes: Traços da personalidade, Habilidades de pensamento, Clima psicológico, Domínio de técnicas e bagagem de conhecimento e Redução de bloqueios. Segundo essa autora, o componente "Traços da personalidade" destaca vários atributos de personalidades existentes em profissionais que vêm se destacando por contribuições criativas, como por exemplo: intenso envolvimento no trabalho realizado, atitude de otimismo aliada à coragem para correr riscos, flexibilidade pessoal, abertura à experiência e tolerância à ambiguidade, autoconfiança, iniciativa e persistência.

O componente "Habilidade de pensamento" refere-se aos componentes do pensamento criativo. Algumas pesquisas identificaram alguns componentes que influenciam o pensamento criativo, tais como: fluência, flexibilidade, originalidade. O componente "Clima psicológico" envolve o clima percebido pelo indivíduo no seu ambiente de trabalho.

O "Domínio de técnicas e bagagem de conhecimento" relaciona-se com as técnicas de resolução criativas de problemas. O desenvolvimento de competências em visualizar os problemas sob diferentes perspectivas e gerar soluções criativas tem sido um dos principais tópicos de programas de treinamento de criatividade. 
O componente "Redução dos bloqueios" envolve fatores do ambiente externo e outros internos à pessoa. Esses bloqueios necessitam ser compreendidos, identificando-se as origens e elaborando estratégias para minimizar algumas dessas barreiras.

Já para Mirshawka Júnior (2003), as principais variáveis que atuam sobre a criatividade seriam:

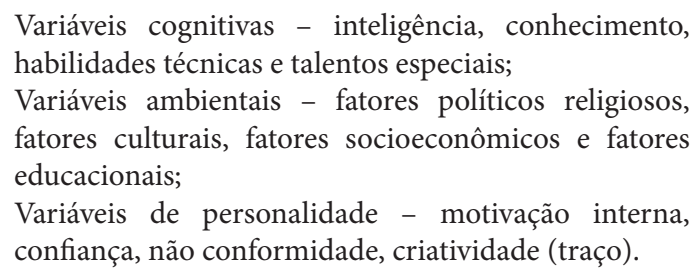

Independente das propostas existentes para identificação das variáveis ou componentes relevantes para a criatividade, alguns autores, entre eles Mirshawka Júnior (2003) e Alencar (1996), apontam para a inter-relação entre a criatividade e a inovação.

A seguir, será demonstrado que a qualidade também pode compor esse relacionamento.

\section{Criatividade, qualidade e inovação}

Criatividade é antes de tudo fazer algo incomum e que seja útil. Surge daí a oportunidade para a melhoria da qualidade e da inovação organizacional. A estrutura organizacional e os modelos de gestão estão em constante evolução para atender ao ritmo dos novos tempos. Essas mudanças ocorrem em todas as direções e muitas organizações têm alterado profundamente a forma de se ver e a forma de trabalhar (DRU; LEMBERG, 1997). Para tais organizações, é de suma importância o processo de inovação. Há um desafio constante na busca da reinvenção do próprio negócio, o que leva à inovação como agregadora de valor empresarial (MOHRMAN; MOHRMAN JR., 1995). Assim, conforme Alencar (1996), inovação e criatividade são domínios muitos próximos: 
A criatividade pode ser considerada como o componente conceitual da inovação, ao passo que a inovação englobaria a concretização e aplicação das novas idéias. Por essa razão, o termo inovação tem sido mais utilizado no nível das organizações e o termo criatividade no nível do indivíduo ou grupo de indivíduos.

Segundo essa autora, um conjunto de elementos é importante para que a inovação se torne uma realidade, conforme Figura 1. E a criatividade, ou ideia criativa, seria um dos componentes.

Figura 1 Fatores necessários à inovação

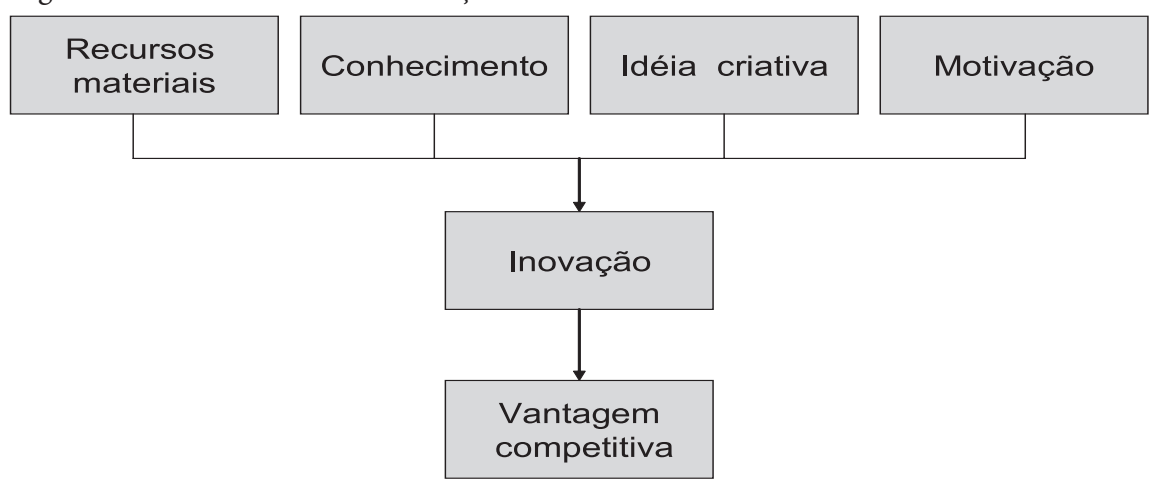

Fonte: Alencar (1996)

Com relação à qualidade, é importante ressaltar que a geração de ideias para a solução de problemas é uma das mais importantes etapas do processo de melhoria contínua. O PDCA é um acrônimo em inglês para Plan (planejar), Do (fazer), Check (Verificar) e Act (agir) e, de acordo com a norma ISO 9001:2000, tem por princípio tornar os processos envolvidos na execução da gestão da qualidade mais claros e ágeis, dividindo-os em quatro principais fases, conforme Figura 2. A fase Act (agir) sugere definir e executar ações de acordo com o avaliado na fase anterior (Check) de forma a melhorar a qualidade e eficiência, aprimorar a execução e corrigir erros. Nesse contexto pode-se identificar que tanto a fase Act como a fase Plan necessitam utilizar o fator criatividade para a definição das ações futuras. 
Figura 2 - PDCA.

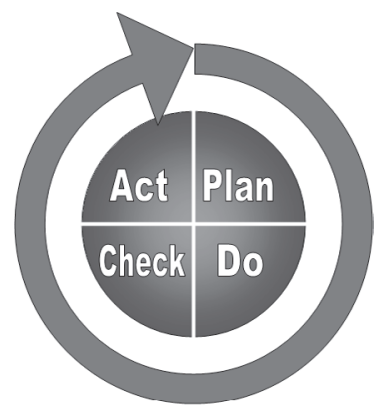

Os modelos de qualidade do processo de desenvolvimento de software CMMI (SEI, 2009) e MPS BR (SOFTEX, 2009) também referenciam áreas chaves, processos e atributos de processo que se preocupam com a Inovação, Análise de Causas de Problemas e Resolução. Mas, na maior parte desses modelos, há mais ênfase nas ferramentas estatísticas e quase nenhuma nas técnicas de criatividade aplicadas à solução de problemas. Em muitos casos, nos quais a solução não é tão evidente, ou não existe uma única solução possível, há necessidade que os problemas sejam tratados de forma inovadora.

Nessas situações, faz-se necessária a combinação do pensamento estatístico com o processo criativo. O pensamento estatístico pode proporcionar o melhor entendimento do problema, mas complementado pelo pensamento criativo possibilita a geração de ideias alternativas e inovadoras para a sua solução, e cria opções originais para os tomadores de decisão de forma a melhorar consequentemente a qualidade dos produtos e serviços disponibilizados.

Segundo Predebon (1998), são considerados inimigos da inovação na empresa: excesso de normas, estratégias rigidamente frontais, postura séria e contida, estrita obediência a números, segmentação total de processos, obediência cega ao consenso e cultura da segurança total. Já Alencar (1996), afirma que existem alguns fatores que inibem a introdução de inovações, dentre eles:

Fatores psicológicos - de natureza individual, que promovem a resistência à inovação, como o conformismo às normas, a baixa propensão a correr riscos, o comodismo e outros; 
Fatores do sistema social - falta de compreensão quanto à inovação e sua necessidade, falta de clareza na comunicação quanto à necessidade da inovação etc.;

Fatores organizacionais - fatores ligados ao grau de centralização de poder decisório, a filosofia e aos valores característicos da organização, a natureza do fluxo de informação, entre outros.

Esses fatores possuem pontos em comum com as barreiras que podem afetar a expressão da criatividade e que serão detalhadas a seguir

\section{Barreiras à expressão da criatividade}

Todo ser humano possui grande potencial criativo, muito embora nem sempre esse potencial seja explorado e expresso em sua totalidade. As análises de pesquisas realizadas sobre criatividade apontam os bloqueios como causas responsáveis por inibir a manifestação do processo criativo.

Segundo Alencar (1996), existem várias barreiras à expressão da criatividade, algumas de caráter social e outras de caráter perceptuais e emocionais. Seriam fatores de caráter social que bloqueiam a criatividade em uma organização:

cultura organizacional - crenças, normas, sentimentos compartilhados pelos membros da organização; e

clima psicológico - estímulos ao comportamento criativo, liberdade para inovar, estímulo a expressão de opiniões.

A cultura, o clima e a estrutura organizacional podem estimular ou bloquear a criatividade do indivíduo. Nas organizações nas quais o poder decisório é centralizado ou predomina a existência de processos formais e rígidos, percebe-se a existência de barreiras à proposição de inovações (ALENCAR, 1997a). Amabile (1999) defende a ideia que "sufocar a criatividade é fácil. Difícil é estimulá-la”. Diz também, que "a criatividade é minada diariamente nas organizações, ainda que in- 
voluntariamente, devido a posturas gerenciais, que se preocupam prioritariamente com coordenação, produtividade e controle." Assim, as atitudes gerenciais tanto podem estimular como inibir as propostas de inovação.

Considerando barreira de caráter perceptual/emocional, o bloqueio pode ocorrer considerando um conjunto de atitudes, características e comportamentos que podem facilitar ou reduzir o comportamento criativo. As barreiras perceptuais/emocionais são construídas lentamente no decorrer da vida do indivíduo. $\mathrm{O}$ comportamento das pessoas que o rodeiam, ainda que em expressões sutis como um sorriso ou uma expressão facial, fazem o indivíduo internalizar formas e tipos de pensamento que se tornam, com o passar do tempo, mais difíceis de romper. As barreiras perceptuais impedem a pessoa de perceber o problema ou informação necessária para resolvê-la. As barreiras emocionais dificultam o aproveitamento das potencialidades criativas. São considerados exemplos de barreiras: apatia, baixa tolerância à mudança, insegurança, medo do fracasso, sentimentos de inferioridade e outros (ALENCAR, 2000).

Segundo Mirshawka (2003), a forma mais simples e eficiente para avaliar a criatividade é fazer um conjunto de perguntas que permitam identificar os obstáculos e facilitadores no que se refere à criatividade. Outros autores como Alencar (2000) e Predebon (2003) sugerem conhecimentos e ferramentas necessárias para identificar fatores que restringem ou limitam a capacidade criativa. Isso permitiria equipar o empregado para o uso mais efetivo da criatividade, instigando práticas de habilidades existentes, mas que permanecem subutilizadas.

Independentemente da forma de análise a ser realizada, é importante, inicialmente, estudar a real necessidade do fator criatividade para a organização, de forma a alinhar a necessidade organizacional com o nível de criatividade exigido de seus empregados. 


\section{Importância da criatividade, qualidade e inovação para o segmento bancário, especificamente para a área de inovação em TI}

Na visão de Moraes (2003), a nova realidade do ambiente financeiro mundial tem obrigado as instituições financeiras à redefinição de suas estruturas de negócios. É necessário mais ousadia nas atividades de captação e manutenção de clientes e o estabelecimento de novos modelos de relacionamento. Essa conjuntura também tem exigido a adoção de novas estratégias com relação aos seus produtos, serviços e controles internos, de forma a garantir a sustentação no mercado.

O setor de serviços financeiros é o que mais utiliza sistemas de informação e tecnologia (KULJIS; SCOBLE, 1997). E é principalmente a tecnologia, nesse segmento que vai permitir ou proporcionar a inovação, por meio da busca da criação de um valor novo para o cliente, ao oferecer diferenciais, e não necessariamente associado a novos produtos.

A área de Inovação em TI da organização bancária pesquisada tem como missão a prospecção e padronização de soluções tecnológicas, por meio de políticas e arquiteturas corporativas, para sustentar os negócios da organização. Para executar essa missão, a inovação e a preocupação com a qualidade são competências necessárias aos seus empregados. Segundo Siqueira (2007), inovação pode ser definida como a implementação de algo novo, mas a implementação de algo novo ou significativo somente existe se a ideia original for julgada valiosa (com qualidade) e colocada em prática, e é nesse escopo que se insere a criatividade.

Foi isso que motivou a escolha da área para esta pesquisa sobre a criatividade. Obteve-se o patrocínio e autorização para a elaboração da pesquisa junto aos gerentes e empregados, buscando mapear os fatores que afetam a criatividade com o propósito de nortear as possíveis ações para a sua potencialização.

\section{A pesquisa}

Para esta pesquisa, optou-se por utilizar o modelo para desenvolvimento da criatividade proposto por Alencar (1993) e focou-se, inicialmente, nos domínios 
Traços da personalidade, Clima psicológico e Redução de bloqueios. O objetivo foi identificar a percepção dos domínios relacionados à criatividade das pessoas que trabalhavam na área de estudo, que tem como um de seus objetivos a inovação e a qualidade. É interessante ressaltar que alguns desses domínios são parcialmente similares a algumas das variáveis propostas por Mirshawka Júnior (2003): cognitivas, ambientais e de personalidade. Com foco nos domínios propostos, mapearam-se as barreiras de caráter social e de caráter perceptual/emocional.

Para o ambiente de estudo, uma organização bancária federal, foi customizado o questionário "Inventário de Barreiras à Criatividade Pessoal", construído por Alencar (1999). Algumas questões foram incluídas e outras foram reformuladas, considerando as necessidades do ambiente estudado e também as barreiras à inovação citadas por Predebon (1998).

Foi utilizada a escala de Likert (MARTINS, 2006) com cinco graus de variação para as respostas (discordo plenamente, discordo pouco, discordo, concordo pouco e concordo plenamente). O questionário adaptado foi disponibilizado na Intranet da organização para ser respondido pelos empregados/contratados da área, durante os meses de junho e julho de 2007.

\subsection{Características da população}

Participaram do estudo 38 respondentes do total de 51 empregados, o que corresponde a $74 \%$ da população. Do total de respondentes, $62 \%$ tinham entre $31 \mathrm{e}$ 50 anos de idade, sendo que a idade média da amostra foi de 36,0 anos.

Com relação ao tempo na organização, 55\% da amostra trabalha a menos de 10 anos na organização e 45\% trabalha a mais de 15 anos na organização. Avaliando o grau de escolaridade, $63 \%$ dos respondentes possuem nível superior ou especialização. A análise dos cargos e funções dos participantes demonstrou que $23 \%$ ocupavam funções gerenciais e que o restante $77 \%$ eram técnicos. 


\subsection{Resultados obtidos}

Foram incluídas duas questões no questionário visando:

- identificar a importância da criatividade no desempenho das funções; e

- identificar o sentimento dos respondentes com relação à sua criatividade, ou seja, se se acham pessoas criativas ou não

Com relação ao primeiro questionamento, 90\% (34) respondentes concordam (plenamente ou pouco) com a alta importância da criatividade no desempenho de suas funções. Considerando o questionamento se são pessoas criativas, $76 \%$ (29) respondentes concordam (plenamente ou pouco) que são pessoas criativas.

Estudos chamam a atenção para o papel da percepção e avaliação de si mesmo na orientação e controle do próprio comportamento e sugerem que, se o indivíduo se percebe e se avalia como criativo, ele tende a ter mais confiança em expressar ideias e em exibir comportamento criativo. Por outro lado, se o indivíduo se percebe não criativo, essa percepção irá refletir em suas ações, limitando as possibilidades de uma expressão mais plena de seu potencial e talento (MARKUS; WURF, 1987 apud ALENCAR, 1997b) Analisando as demais questões com relação às barreiras de caráter social e de caráter perceptuais e emocionais, identificaram-se os seguintes resultados mais significativos, ou seja, resultados que obtiveram um percentual mais representativo frente aos demais resultados:

Barreiras de Caráter social - com relação a tempo e recursos (Figura 3):

- 19 respondentes concordam que se tivessem mais tempo, poderiam utilizar melhor a sua criatividade;

- 20 participantes seriam mais criativos se tivessem mais tempo para elaborar suas ideias;

- 29 respondentes identificaram que com mais recursos (equipamentos, livros, dinheiro etc.) para por suas ideias em prática, poderiam aumentar a sua criatividade; $\mathrm{e}$

- 28 participantes concordam que o nível de criatividade aumentaria, se pudessem utilizar a Internet nas pesquisas para o trabalho. 
As barreiras sociais envolvem a identificação de sentimentos compartilhados pelos membros da organização. A análise das respostas (Figura 3) permite concluir que um quantitativo acima de $50 \%$ dos participantes identifica barreiras sociais com relação a tempo e recursos. Com relação à utilização da Internet, é importante ressaltar que, na empresa estudada, o acesso à Internet é restrito para os técnicos, o que ratifica a resposta obtida com relação ao uso da Internet. Se um dos objetivos da área pesquisada é a prospecção de soluções tecnológicas, esse tipo de restrição não permite a estimulação do comportamento criativo.

Figura 3 - Barreiras de caráter social com relação a tempo e recursos - percentual

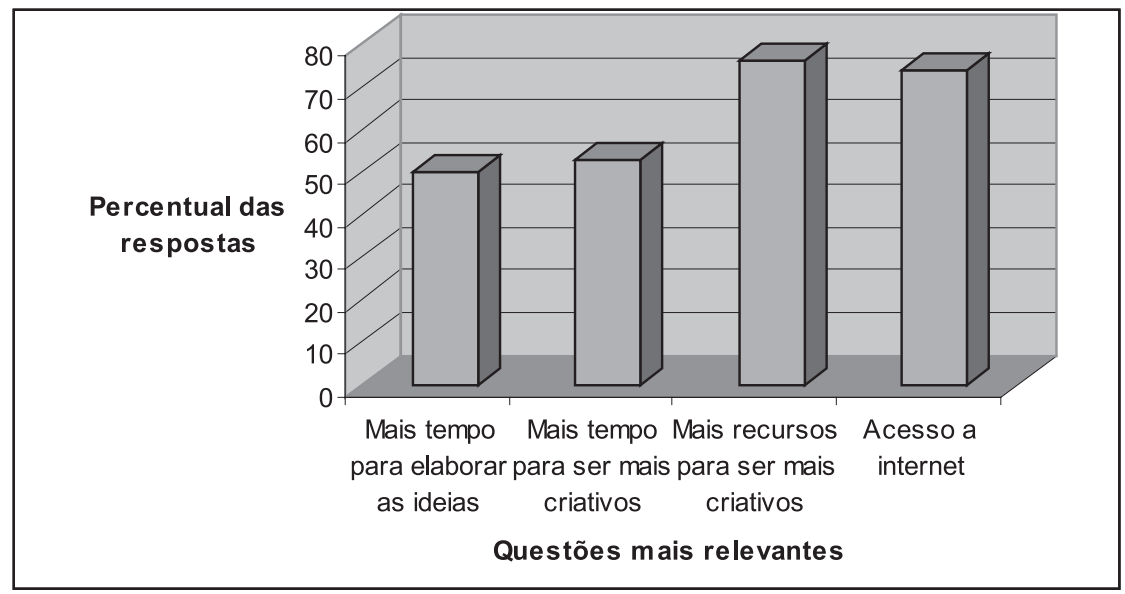

Barreiras de Caráter social - com relação ao reconhecimento e incentivo (Figura 4):

- 27 respondentes concordam que, se houvesse maior reconhecimento do trabalho criativo, sua criatividade seria melhorada;

- 24 participantes seriam mais criativos, se suas ideias fossem mais valorizadas;

- 23 indivíduos identificaram que, se fossem mais encorajados a expor o que pensam, o nível de criatividade seria maior; 
- 29 respondentes utilizariam melhor sua criatividade, se tivessem mais oportunidades de por em prática as suas ideias;

- 22 indivíduos aumentariam a sua criatividade, se fossem mais incentivados pelos colegas;

- 22 participantes seriam mais criativos, se houvesse mais respeito à diferença entre as pessoas;

- 24 respondentes identificaram que o aumento de cooperação entre as pessoas incrementaria a criatividade; $\mathrm{e}$

- 24 indivíduos responderam que, se tivessem mais oportunidades de explorar seu potencial, o nível de criatividade seria melhorado.

Figura 4 - Barreiras de Caráter social - com relação ao reconhecimento e incentivo percentual

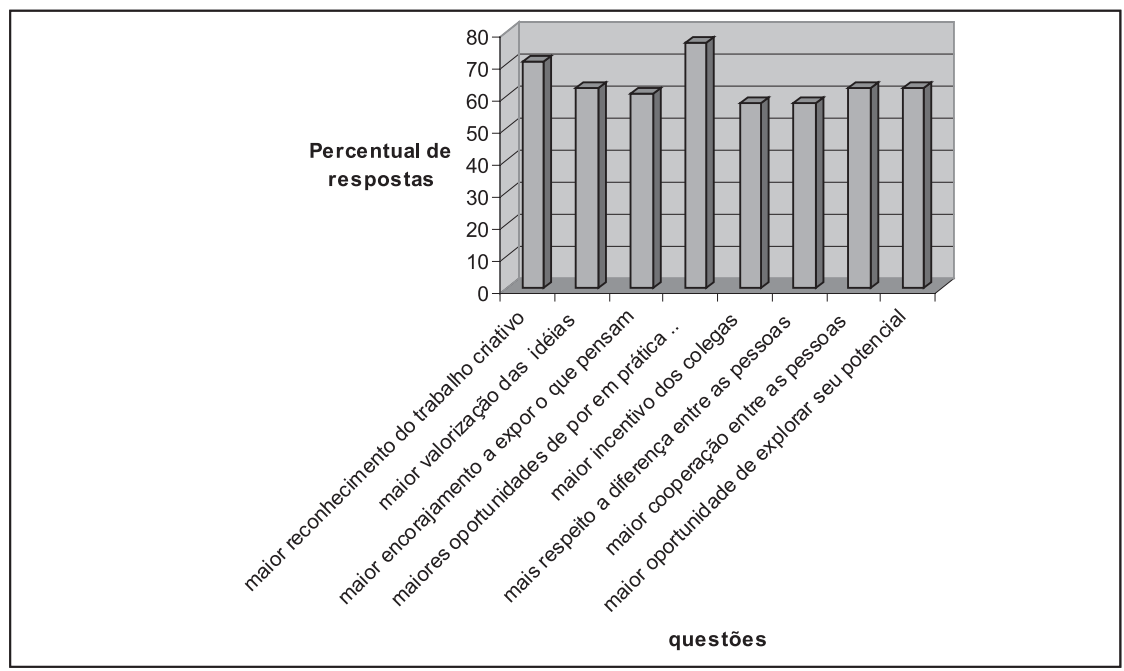

Amabile (1999) cita que a criatividade é diariamente boicotada nas organizações, devido a posturas gerenciais que focam principalmente a coordenação, a produtividade e o controle. Os resultados demonstram que, um quantitativo acima de $58 \%$ dos participantes da pesquisa considera as atitudes gerenciais e dos colegas da área estudada desestimulantes com relação à criatividade. Esses comportamentos tendem a inibir propostas de inovação, tão importantes para a área estudada. 
Barreiras de caráter perceptuais e emocionais (Figura 5)

- 23 respondentes consideram que, se não fossem tão críticos consigo mesmos, seriam mais criativos;

- 20 participantes seriam mais criativos, se fossem menos perfeccionistas;

- 24 indivíduos responderam que, se aproveitassem melhor as oportunidades que surgem de exercitar a criatividade, esta seria incrementada;

- 25 respondentes identificaram que seriam mais criativos, se exercitassem mais o hábito de buscar ideias novas;

- 19 participantes consideram que, se tivessem maior disposição para correr mais riscos, o nível de criatividade aumentaria; e

- 20 indivíduos consideram que seriam mais criativos, se tivessem mais conhecimentos.

Figura 5 - Barreiras de caráter perceptuais e emocionais - percentual

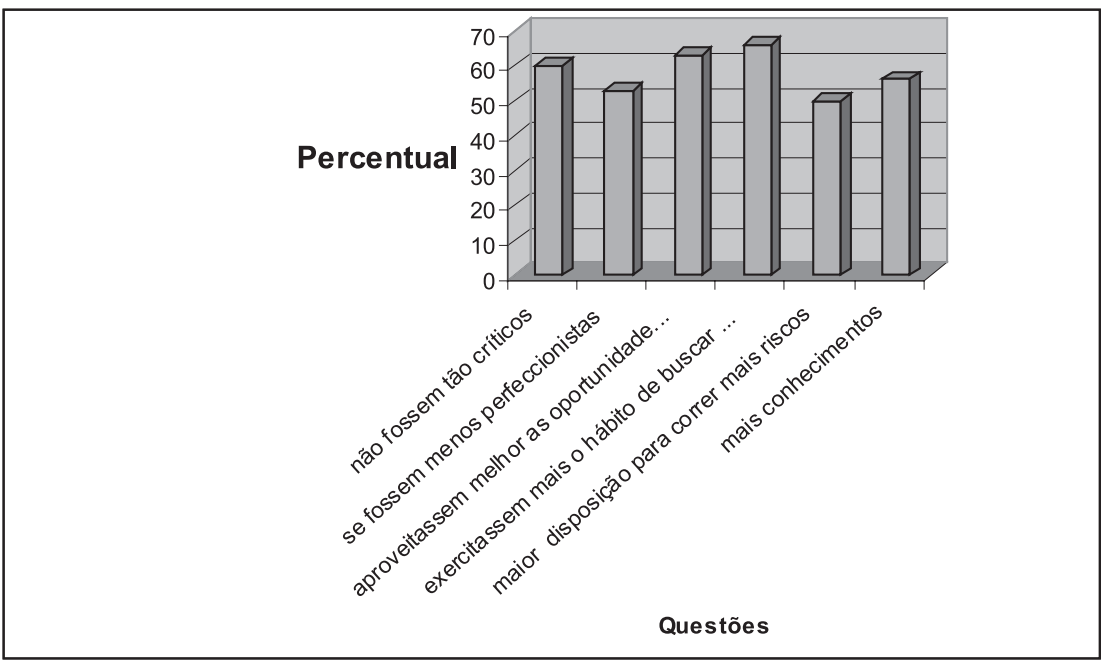

As barreiras de caráter perceptuais e emocionais são construídas ao longo da vida do indivíduo e, como tal, dependem de ações individuais e/ou coorporativas para serem trabalhadas. Os resultados apresentam que, para mais de $53 \%$ dos 
participantes, existem pontos que podem ser melhorados (individual ou coletivamente) para aumento do nível de criatividade.

\section{Considerações finais}

O presente trabalho buscou identificar algumas barreiras à criatividade na TI em uma organização bancária governamental. Com esse diagnóstico, a organização pode investir em ações que melhorem o nível de criatividade, agregando maior valor aos seus serviços e produtos, gerando inovação e melhorando a qualidade.

Tratada como processo, a criatividade pode ser estudada, compreendida e aperfeiçoada (SIQUEIRA, 2007). A busca pela quebra de barreiras à criatividade deve ser uma constante tanto individual, quanto organizacional. Devem ser cultivados valores, práticas e comportamentos "no sentido de despertar a consciência dos indivíduos e das organizações para o potencial e poder dos seus recursos criativos que permanecem, muitas vezes, adormecidos e bloqueados, em função de um ambiente destituído de possibilidades para que o indivíduo encontre um interesse renovado em atuar de uma forma criativa e inovadora" (ALENCAR, 1997a).

Promover as mudanças para melhor aproveitamento dos recursos criativos é um processo difícil e lento, que exige trabalho consciente para libertar alguns desses bloqueios. Predebon (1998) afirma que nenhuma abordagem para desenvolver a criatividade consegue mudar instantaneamente a pessoa, a organização ou mesmo acrescentar potencialidades no campo mental dos indivíduos. Esse deve ser um trabalho organizacional contínuo para modificar a cultura, reduzir as barreiras e incentivar a inovação.

Existem três grupos de caminhos para o desenvolvimento da criatividade (PREDEBON, 1998):

estruturais - oferecem esquemas mais ou menos prontos para dirigir o raciocínio em direção a soluções criativas; 


\begin{abstract}
Abordagens comportamentais - buscam anular os bloqueios normais do indivíduo por meio de exercícios geradores de iniciativa e autoconfiança; e Abordagens atitudinais - baseadas nas mudanças na pessoa que se processam por meio de trabalho no campo psicológico, com a procura de uma expressão mais plena do potencial criativo.
\end{abstract}

Predebon (1998) ainda afirma que muitos recursos podem ser utilizados para o desenvolvimento da criatividade. A leitura pode ser utilizada como treinamento de criatividade. O brainstorm pode ser aplicado, inclusive para identificar ações que melhorariam a criatividade e eliminariam parte das barreiras identificadas como ausência de incentivo e cooperação. Ações para fomentar a comunicação e a complementaridade, a comunicação do líder e o clima democrático devem ser definidas e implementadas para atingimento dessa meta.

Na visão de Alencar (2000), o desenvolvimento de uma cultura criativa deve propiciar treinamentos voltados para a atualização do conhecimento e desenvolvimento de habilidades criativas, estabelecer metas para se alcançar produtos criativos e encorajar discussão e comunicação de ideias entre os membros das equipes com premiação das ideias e produtos criativos e ausência de punições a fracassos eventuais. É fundamental o estabelecimento de um clima de confiança.

Para pesquisas futuras, sugere-se avaliar o nível de criatividade das atividades voltadas especificamente para o desenvolvimento de software, buscando identificar as principais necessidades e barreiras com relação à criatividade.

\title{
Barriers to creativity's expression that can influence quality and innovation in IT
}

\section{Abstract}

The importance and need of quality in IT is already an international consensus. The innovation impact for the competitive differential is also recognized by many authors and organizations. The creativity, considered as a conceptual com- 
ponent of innovation, has been being stimulated by organizations which aim is an ongoing enhancement and the conception of new products and services. In this article, there is an attempt to identify the relevance of the creativity to the innovation and quality, outlining the obstacles for its expression on an IT area of a governmental banking organization. Some suggestions are also shown for the development at the organizational creativity.

Keywords: Creativity. Innovation. Quality. Obstacles for creativity expression.

\section{Referências}

ALENCAR, E. S.; FLEITH, D. S. Barreiras à criatividade pessoal entre professores de distintos níveis de ensino. Psicol. Reflex. Crit., Porto Alegre, v. 16, n. 1, 2003.

ALENCAR, Eunice M. L. Soriano de. A gerência da criatividade. São Paulo: Makron Books, 1996.

ALENCAR, Eunice M. L. Soriano de. A gerência da criatividade: abrindo as janelas para a criatividade pessoal e nas organizações. São Paulo: Makron Books,1997a.

ALENCAR, Eunice M. L. Soriano de. Criatividade. Brasília: UnB, 1993.

ALENCAR, Eunice M. L. Soriano de. O estímulo à criatividade no contexto universitário. Psicol. esc. educ., Campinas, v. 1, n. 2-3, p. 29-37, 1997b.

ALENCAR, Eunice M. L. Soriano de. O processo da criatividade. São Paulo: Makron Books, 2000.

ALENCAR, Eunice M. L. Soriano de. Psicologia da criatividade. Porto Alegre: Artes médicas, 1986.

AMABILE, T. Como (não) matar a criatividade. HSM Management, Barueri, p. 110-115, jan./fev. 1999.

ASSOCIAÇÃO BRASILEIRA DE NORMAS TÉCNICAS. NBR ISO 9001: Sistemas de gestão da qualidade: requisitos. Rio de Janeiro, 2000. 
BRUNO-FARIA, M. F; ALENCAR, E. M. L. S. Estímulos e barreiras à criatividade no ambiente de trabalho. Revista de Administração, São Paulo, v. 31, n. 2, p. 50-61, 1996.

CARVALHO, Bruno. O que é a criatividade? [S.1.], 2005. Disponível em: <http:// www.criativ.pro.br/index.php? option $=$ com_content $\&$ task $=$ view $\&$ id $=68 \&$ Item $\mathrm{id}=37>$ Acesso em: 24 ago.2007.

DRU, J. M., LEMBERG, R. Drisrupt your business. Journal of Business Strategy, [S. 1.] v. 18, n. 3 , p. $24-30$, maio/jun. 1997.

KULJIS, Jasna; SCOBLE, Chris. Problems of management and decision making in Multinational Banking. IEEE, 1060-3425, p. 398-405, 1997.

MARTINS, Gilberto de Andrade. Estudo de caso: uma estratégica de pesquisa. São Paulo: Atlas, 2006.

MIRSHAWKA JUNIOR, Victor. Qualidade da criatividade. São Paulo: DVS, 2003. V. 1.

MIRSHAWKA JUNIOR, Victor. Qualidade da criatividade. São Paulo: DVS, 2003. v. 2.

MOHRMAN, S. A., MOHRMAN JR., A. M. Mudanças organizacionais e aprendizado. In: Galbraith, J.; Lawler III, E. E. (Org.) Organizando para competir no futuro. Rio de Janeiro: Makron Books, 1995. p. 69-89.

MORAES, José Cássio Froes de. Análise da eficácia da disseminação de conhecimentos sobre controles internos após sua implementação no Banco do Brasil. 135p. 2003. Dissertação (Mestrado em Engenharia da produção)-Universidade Federal de Santa Catarina, Florianópolis, 2003.

NOVAES, M. H. Psicologia da criatividade. 5. ed. Petrópolis: Vozes, 1980.

PREDEBON, José. Criatividade hoje: como se pratica, aprende e ensina. São Paulo: Atlas, 2003.

PREDEBON, José. Criatividade. São Paulo: Atlas, 1998.

SIQUEIRA J. Criatividade e inovação. [S.1.], jan. 2007. Disponível em: <http:// criatividadeaplicada.com/2007/01/24/criatividade-e-inovao/>. Acesso em: 01 jan 2010 . 
SEI. CMMI: capability maturity model integration. Disponível em: $<\mathrm{http} / / / \mathrm{www}$. sei.cmu.edu/cmmi>. Acesso em: 01 jan.2009.

SOFTEX. Melhoria de processo do software brasileiro: guia geral versão 1.4. Jun. 2009. Disponível em: <http://www.softex.br/mpsbr/_guias/MPS.BR_Guia_Geral_ V1.4.pdf>. Acesso em: 01 jan 2010.

STERNBERG, R. J.; LUBART, T. I. The concept of creativity: prospects and paradigms. In: Handbook of creativity. Cambridge, UK: Cambridge University, 1999. 


\section{Para publicar na revista Universitas Gestão e TI, entre no endereço eletrônico www.publicacoesacademicas.uniceub.br. Observe as normas de publicação, facilitando e agilizando o trabalho de edição.}

